Revista Iberoamericana, Vol. LXXV, Núm. 226, Enero-Marzo 2009, 153-166

\title{
LA GOZADORA DEL DOLOR Y OTRAS NOVELAS DE GRAZIELLA GARBALOSA: EROTISMO, NATURALISMO, Y VANGUARDISMO EN LA NARRATIVA FEMENINA CUBANA DE LOS AÑOS VEINTE ${ }^{1}$
}

\author{
POR \\ Catharina VALLEJo \\ Concordia University, Montreal
}

Hacia el final del siglo xix el mundo occidental sufre cambios radicales: urbanización, industrialización, capitalización, aburguesamiento -todos factores participantes de un proceso que se ha dado en llamar “modernización”. Parte de ese proceso lo constituía un paulatino y difícil reconocimiento de la mujer como sujeto - del discurso, del mundo, y de su propio cuerpo. En Cuba, la época de fines del siglo xix y principios del xx se presentó como aun más trastornada quizás que en otras partes del mundo hispanoamericano. Las guerras de independencia, la intervención y ocupación estadounidense, la importación de modales extranjeros, y cambios radicales en la sociedad y en la política crearon una gran inestabilidad, pero también un ambiente culturalmente dinámico y de ahí una interesante productividad cultural. Sobre todo los años que van de 1921 a 1933 se caracterizan por un gran torbellino artístico de vanguardia. Es una época de crisis económica, protestas políticas, huelgas estudiantiles y de obreros, creación de asociaciones, revistas y manifiestos literarios de vanguardia, y formación de agrupaciones sindicales y políticas (anarquistas, marxistas, anticlericales, feministas y otras muchas).

Es notable que en esas circunstancias las mujeres cubanas participaran en esta actividad política y cultural en gran número y en gran calidad. En efecto, la segunda y tercera década del siglo xx deben considerarse de suma importancia en el quehacer cultural de las mujeres. Se adquiere la aprobación de la Ley del Divorcio en 1918 y se establece el Club Femenino de Cuba (1918), que buscaba el sufragio femenino y que participó de la formación de la Federación Nacional de

1 Este trabajo se basa en una ponencia leída en el congreso "Erotismo y representación de la mujer en la cultura latinoamericana y caribeña”, celebrado en Casa de las Américas en La Habana en febrero del 2002. Se ha reelaborado a partir de un texto escrito para una colección de trabajos sobre las actividades culturales y literarias de las mujeres cubanas en la década de los veinte (novelistas, ensayistas, poetas y educadoras como Ofelia Rodríguez Acosta, Dulce María Loynaz, Mariblanca Sabas Alomá, María Luisa Dolz y otras), proyecto que no se ha podido realizar debido a la muerte, prematura y trágica, de su coordinadora Susana Montero Sánchez, a cuya memoria dedico este ensayo. 
Asociaciones Femeninas de Cuba en 1921, compuesta por unos 8.000 miembros. Esta agrupación patrocinó en 1923 el Primer Congreso Nacional de Mujeres -el primero de América Latina-, seguido por un Segundo Congreso en 1925 (González Pagés 54-70). El grupo de mujeres poetas, cuentistas y ensayistas cubanas fue grande y activo: Dulce María Loynaz, Dulce María Borrero, Ofelia Rodríguez Acosta (quien produjo dos novelas en la década de los veinte, ambas de atrevido “feminismo", El triunfo de la débil presa, de 1926, y La vida manda, de 1929), y Graciela (o Graziella, como ella prefería) Garbalosa (1895-1977). Este trabajo investigará la producción cubana de esta última escritora, poniendo especial énfasis en La gozadora del dolor (1922) -la primera novela de contenido erótico escrita por una mujer cubana-, así como en algunos de los elementos vanguardistas de su producción novelística restante, con la esperanza de que tal examen permita un mayor reconocimiento crítico.

En Hispanoamérica, la novela tardó en dar entrada a las mujeres productoras; ha sido un género de difícil conquista para las escritoras. A diferencia de las escritoras británicas, por ejemplo, que fueron la mayoría y, en gran parte las primeras productoras de la novela en su país, el género narrativo fue vedado a las escritoras hispanoamericanas por referir a un aspecto del mundo exterior al hogar. Es de notar, sin embargo, que entre las primeras novelistas hispanoamericanas del siglo XIX se cuentan varias cubanas: en primer lugar Gertrudis Gómez de Avellaneda (Dos mujeres, Sab, entre otras); también Luisa Pérez de Zambrana, quien escribió Angélica y Estrella hacia 1860 (aunque no la publicó); y Virginia Auber, una gallega radicada en Cuba por treinta y tantos años y productora de una docena de novelas entre 1845 y 1860. A fines de siglo son pocas las novelistas nacidas en suelo cubano; publica la española Eva Canel varias novelas en La Habana (entre otras: Manolín en 1891 y Oremus en 1893), aparecen una Ynés Domínguez de G. Lauzán con Una madre de familia en 1888, Avelina Correa con La perla hereditaria de 1894, y Georgina ‘de Flores' (pseud. de Rencurrell) con Adelfa en 1899. En once años se cuentan tres novelas, todas ellas firmemente ancladas aún en el romanticismo, y sus autoras muy ignoradas. ${ }^{2}$ Después de esa fecha, sólo se publica una que otra novela histórica (por ejemplo, Calixto García, escrita por Fermina de Cárdenas en 1909), pero las novelistas femeninas son notables en su ausencia. Habría que esperar hasta la década de 1920 para poder encontrar nuevamente mujeres escritoras de novelas en Cuba. ${ }^{3}$ No hay en Cuba una Ana Roqué ni una Carmela Eulate Sanjurjo, como en Puerto Rico -productoras de novelas variadas- ni, como en República

2 Es de notar, efectivamente, la parca información disponible sobre esas autoras, así como la dificultad para encontrar sus obras.

3 Ver González Curquejo, Susana Montero 1989, y Catherine Davies, y nótese que en esos veinte a treinta años se publican otras tantas novelas escritas por hombres. 
Dominicana, una Amalia Francasci -primera novelista de la República, autora de dos novelas y un volumen de cuentos entre 1892 y 1902-, autoras de novelas redolentes aun de romanticismo.

La producción novelística de principios del siglo xx en Cuba se ocupaba de los grandes conflictos psicológicos, sociales y políticos de la época, sobre todo manifestados, por un lado, a través de un naturalismo de "intenso relieve sociológico [...] impregnado de un fuerte sabor local” y revivido a partir de 1912 (Historia de la literatura cubana 149) y, por otro, a través del romanticismo rezagado en los interminables folletines periodísticos traducidos de escritores (y escritoras) extranjeros. Para principios de los años veinte, el interés estaba ya en la "búsqueda de una expresión nueva y el rescate de la nacionalidad" (Historia 188). Los novelistas cubanos más atrevidos del segundo decenio del siglo xx, los más vanguardistas en expresión y temática, como Alfonso Hernández Catá (18851940) y Emilio Bobadilla (1861-1921), publicaban en Madrid y aún hoy no gozan de gran consideración en la historia literaria cubana. ${ }^{4}$ En la época, las novelas eróticas de estos escritores se vieron como de carácter cuasi antipatriótico en un momento que, desde José Martí y otros padres de la patria, valoraba el amor patrio por sobre todo, y la novela como género se vio precisamente como instrumento para fomentar la constitución de una identidad nacional. La profanación religiosa en los actos sexuales, la ingerencia de drogas, la tisis y la atracción sensual por el cuerpo muerto señalan en la obra de Catá (por ejemplo en su Novela erótica de 1909) una degeneración típica del espíritu fin de siècle. Catá también publicó El placer de sufrir (1920) y El aborto (1922), de que aún demuestran ese mismo ímpetu. Las “enfermizas aberraciones” (11) de sensualismo de En la noche dormida de Emilio Bobadilla (publicada en 1914, y que alcanzó una segunda edición en 1920), por otro lado, se justificaron por ser "análisis" al estilo naturalista; era "un libro escrito después de haber vivido muy intensamente, y sangrante de realidad, observación y espíritu” (9), un estudio psicológico de un caso clínico (12), como observan varios comentaristas citados a manera de prólogo a la obra. Sobre todo las novelas de Bobadilla (a partir de A fuego lento, primera edición de 1903), causaron escándalo y no fueron publicadas en Cuba en esa época. De hecho, en España se publicaban en gran cantidad novelas "eróticas” y/o de contenido crudo al estilo naturalista, las que gozaban de gran aprecio público, reeditándose con regularidad. Además de Bobadilla y Catá, publicaron en España, con reediciones en Latinoamérica (sobre todo en México y Buenos Aires), el prolífero Felipe Trigo (1864-1916) y Eduardo

4 Sin embargo, Víctor Fowler considera que En la noche dormida de Bobadilla "constituye uno de los documentos más reveladores y complejos de las mitologías asociadas a la representación del erotismo y la sexualidad en nuestra literatura, además de ser de los más atrevidos textos de nuestro naturalismo literario" (41). 
Zamacois (1873 o 1876-1972; por ejemplo, Incesto, de 1900). Este último tuvo estrechos lazos con Cuba; nació en Pinar del Río, pasó dos estadías más o menos largas en La Habana en 1913 y 1918, y fue muy conocido en el país. En 1910, su novela Los inmigrantes apareció en forma seriada en el periódico habanero El Mundo. Es evidente que esta producción peninsular se conocía en la isla, donde aún dominaba el naturalismo hasta entrados los años veinte (Historia 129), y que estas obras repercutieron en las de Graziella Garbalosa -basta recalcar el título de su primera novela.

Según lo ha indicado Rita Felski, a principios del siglo xx la creencia en la función espiritual y moral del arte cedió para dar lugar a un realismo agresivo que impulsó la representación de los detalles de una realidad corrompida (117). El realismo de Las honradas (1917) y Las impuras (1917) del cubano Miguel de Carrión, consideradas en su época como representaciones descarnadas de la realidad, causó el furor de los que tenían autoridad moral. ${ }^{5}$ Gwen Kirkpatrick explica que las consecuencias literarias de los grandes cambios sociales y culturales ocurridos en el mundo occidental a principios del siglo $\mathrm{xx}$ acarrearon perspectivas diferentes hacia el papel que el artista desempeñaba, así como hacia el sujeto enunciador o narrativo (3). Se comenzaba a tener conciencia de la significación de la voz que se expresaba, y esa conciencia dio lugar a muchos experimentos de una textualidad vanguardista. Parte de esa vanguardia, Graziella Garbalosa publica en 1922 en La Habana La gozadora del dolor, ${ }^{6}$ seguida por El relicario. Novela de costumbres cubanas en 1923, ${ }^{7}$ Una mujer que sabe mirar, publicada en México en $1927,{ }^{8}$ y Más arriba está el sol, que se publica en La Habana en 1931. Todas esas obras evidencian una gran conciencia de experimentos narrativos muy de la época vanguardista, y notable para una mujer escritora. Es, pues, Graziella Garbalosa un caso extraordinario en el ambiente artístico cubano, sobre todo en el de la primera mitad del siglo xx. Actriz, cantante, prolífica poeta y prosista, participa muy activamente del ambiente de vanguardia y protesta estudiantil, lo que motiva

5 En efecto, los periódicos de la época revelan que hubo intentos de prohibir la lectura de Las honradas a las jóvenes solteras (Historia de la literatura cubana 140).

6 Según Susana Montero, para 1950 llegan a sesenta las novelistas cubanas (1989, 8). Con excepción hecha de algunas obras de Ofelia Rodríguez-Acosta a finales de la década de 1920, pocas, sin embargo, serán como La gozadora del dolor.

7 Jorge Mañach se ocupa someramente de esta novela -y de otra de María Catasús- en El diario de la Marina del 30 de enero de 1924.

8 De esta novela salió una reseña en la reconocida revista limeña Amauta, dirigida por Martiátegui en enero de 1928, y firmada Martín Adán. La novela presenta "entereza de ánimo y un feminismo, aunque sincero, cuerdo y práctico, [...] Quizás algo de Vargas Vila, de Gabriela Mistral [...] Un problema de América, y una mujer que protesta en nombre de su sexo, de su raza y de su casta [...] [R]epetimos, la novela está muy bien, como se dice, técnicamente”. 
su partida repentina para México en 1926. Regresa a Cuba en 1928, pero a partir de entonces comparte su vida entre Cuba y México. Publica artículos, poemas y crónicas sobre una amplia gama de temas en los mayores diarios de ambos países (El Diario de la Marina, Bohemia, Social, Carteles). Mantiene correspondencia y amistad con grandes figuras intelectuales y artísticas de la vanguardia, como Ernest Hemingway, Julio Antonio Mella, Rubén Martínez Villena, Diego Rivera, Gerardo Murillo, Tina Modotti, y José Carlos Mariátegui. Después de la revolución de 1959 mantiene su residencia en Cuba, donde fallece en $1977 .^{9}$

En 1920, Garbalosa había publicado un volumen de poesías, La juguetería del amor. Aun ésta, su primera obra, evidencia una conciencia de los diferentes aspectos de la sensualidad y de su representación textual. Queda claro que ella participaba del incipiente movimiento vanguardista que comenzaba a fomentarse en Cuba en los años veinte y que presentaba una conciencia de su propio quehacer así como experimentos creativos de toda clase, evidenciados en las revistas de la época, por ejemplo Social (en la cual colaboraba Garbalosa de manera activa entre 1917 y 1924), Bohemia y Fígaro. Los prólogos de todas las obras de Graziella Garbalosa presentan sus reflexiones sobre la escritura y complementan la obra creativa de manera extraordinaria. En La juguetería anuncia que su libro de poemas es "una pequeña gruta de pasión, dolor, ingenuidad y ternura. Gruta que recama y embellece la hiedra del amor, el erotismo, que es el atavío más en boga en nuestra literatura del siglo xx" (3). Su expresión escritural es tanto más atrevida en cuanto se recuerda que el sentimiento erótico en tanto experiencia propia estaba vedado a las mujeres "honradas" hasta bien entrado el siglo xx. La sociedad burguesa, ultra conservadora, era también sexualmente represiva, y mientras que para las mujeres decentes la sexualidad quedaba limitada al matrimonio, la sensualidad y el erotismo quedaban al margen aun de esa institución (Litvak 2). En algunas de sus composiciones poéticas, Graziella Garbalosa retoma la labor iniciada por Nieves Xenes y Mercedes Matamoros, quienes en torno a 1900 llevaron la delantera en la modernización de la expresión poética cubana con respecto a la concepción de la mujer, y participaron de una paulatina textualización del cuerpo femenino en el discurso poético a partir de la conciencia femenina misma -procedimiento fundamental para permitir a la mujer la captación plena del momento presente. En el poema "Copa de bronce"

\footnotetext{
9 Quiero expresar mi profundo agradecimiento a José Alberto Romo Garbalosa, nieto de la escritora, quien me proporcionó datos biográficos y artísticos. A pesar de toda su actividad meritoria, pero quizás a causa de sus peregrinaciones entre dos patrias, se encuentran pocas referencias a su obra. El Diccionario de la literatura cubana, por muchos años referencia esencial, no menciona a Graziella Garbalosa; la más reciente Historia de la literatura cubana (2003) le dedica un breve párrafo, sólo mencionando en nota a pie de página La gozadora del dolor como “cruda novela” (II, 584); no mencionan sus publicaciones periódicas ni la fecha de su muerte.
} 
Garbalosa explora la relación entre la pasión y la escritura poética que la exprese: "Si es el mundo la copa de bronce, / donde vierte licor la Poesía, / los poetas seremos entonces / los borrachos de lírica orgía”, y explicita el deseo de su propio sujeto femenino en este proceso: "(Quiero ser la más grande beoda / de locos ensueños, apurando toda / la copa broncínea del néctar cruel!” (28).

Esta preocupación por la representación textual de la experiencia erótica formará el eje de su primera novela. En ella Garbalosa resalta el énfasis en la necesidad de la escritura (ficcional) para suscitar la pasión, la necesidad de la escritura para formularla y para explicitar las consecuencias. Puede verse este proceso como un intento de retextualización -y de ahí reapropiación- del cuerpo femenino, apartándose de la idealización y la simbolización tradicionales y patriarcales, hacia un reconocimiento de los placeres potenciales de la materia física propia y de las consecuencias de la sumisión a ésta. La gozadora del dolor cuenta los amores de una bailarina y un novelista en La Habana, Cecilia y Óscar, ambos famosos en el ambiente artístico capitalino y quienes, según el propio texto, viven una novela de degeneración a lo fin de siècle en una "canastilla de anacronismos" (110, 87). El novelista (hábil "mercader de frases encomiásticas” [115]) seduce a una vecinita de dieciséis años, “de apellido notable y educación esmerada” (106), que había descubierto el placer de su cuerpo, impulsada a la práctica de la sensualidad con su hermana por medio de la lectura de una novela de Musset. Ella queda encinta, se provoca un aborto y muere. La amante del novelista, Cecilia, entonces lo envenena y se suicida ella misma. Esta trama se aproxima a los melodramas de la época y, como tal, presenta las características de ese modo estético: un fuerte emocionalismo, polaridad moral, estados extremos del existir humano, trama intensa y exagerada (Felski 121-22). Parte del modo melodramático consiste en una retórica de extremos, y la novela presenta escenas de una "graficidad" tanto sensual como realista, "graficidad" textual que encierra una verdad ineludible: que el goce del placer erótico es material, y de ahí conlleva como consecuencia vital -y por tanto necesaria- el dolor, el horror y, en última instancia, la tragedia. En camino a este final determinado, la escritora se lanza a las técnicas del naturalismo no vistas en la novelística cubana hasta ese momento y, en efecto, "audaz aun para nuestra época”, según Susana Montero $(1989,13)$.

La novela presenta dos planos: primero, la vida mundana de la pareja artista, que se funda en la búsqueda y primacía de la belleza sensual y que se juega en la oposición genérica masculino-femenina (se oponen la escritura -obra cerebral, masculina de él-y el baile-obra corpórea, femenina de ella). La segunda dimensión complementa la primera; se trata del más descarnado naturalismo, que describe las consecuencias que tiene la sensualidad humana cuando se lleva a su enlace natural: la procreación, el transcurso del tiempo y sus estragos en el cuerpo humano, hasta 
la muerte. Entre ambos planos, y desde la perspectiva de la bailarina, se formulan los postulados feministas de la época, que se concibieron en extremos absolutos y en términos explícitos de un fuerte odio hacia los hombres.

Desde el principio de la novela se aboga por el respeto a la sexualidad de la mujer; en palabras de Cecilia: “¿Qué ridícula y absurda se le presenta la moral que le impone a las vírgenes el mundo!” (109) y “La mujer insaciable y ardorosa que nace fisiológicamente preparada para satisfacer los apetitos sensuales del hombre, por qué no es respetada en la humana condición de sacerdotisa del Deseo?” (45), hasta el final, cuando Cecilia, la bailarina, en sus últimos momentos lúcidos explica: "Las débiles eran las víctimas, las fuertes serían las niveladoras, para vengar el montón anónimo y sus dolores ocultos... ¡Si por un corto lapso de tiempo todas las mujeres se transformaran en niveladoras, la vida sufriría un cambio transcendental!" (198), ya que las mujeres se vengarían de “la fiera más temible: ¡El Hombre!” (193). Efectivamente, al matar a su amante y así vengarse, de acuerdo a sus criterios de la relación entre los géneros, Cecilia se erige en "niveladora” de la sociedad. Esto en contraste directo con el tradicional "romance" en el que, aunque sea al final de muchos obstáculos y peripecias, "the women dutifully submit to their men" (Sommer 16). En efecto, la novela de Graziella Garbalosa demuestra cuán lejos está de la época de la foundational fiction analizada por Doris Sommer. Doña Bárbara, en la novela epónima publicada sólo unos cuantos años después de La gozadora del dolor, sensual y emprendedora, se muestra como "degenerative by definition" (Sommer 23). La familia no tiene ya un lugar primordial o simbólico en la construcción de la sociedad; más bien, a través de la materialidad de los cuerpos y la muerte de los mismos, la trama señala la corrupción y la violencia moral de una sociedad en crisis. Algunas mujeres son “niveladoras” de las relaciones de género, pero perecen como consecuencia de sus actos.

La novela abarca la gama de las corrientes artísticas y sociales de principios del siglo xx y establece el ambiente sensual a partir de descripciones de los interiores "modernistas" y preciosistas. ${ }^{10}$ La presencia de la autorreflexividad hacia el ambiente y las características estilísticas del modernismo, el vanguardismo y el decadentismo se delatan a través de innegables trazos de ironía. Cecilia anuncia: "voy a ser adorada y haré la ofrenda de mi cuerpo ante el altar de una pasión sublime” (73). En su primer acto de voyeurismo, Óscar espía a Josefina, "núbil Afrodita” (115), en el baño, y le encantan las "dos pomas nacaradas que terminan en dos pétalos de rosa” (107). Lo que queda al final del tiempo, envejecida la belleza en la vida

${ }^{10}$ Por ejemplo: "Los jazmineros que trepan por las columnatas jónicas [...] las columnas, los zócalos y las escaleras del edificio, son de mármoles rosados [...], una fuente de alabastro festoneada con musgos, [...] una otomana [...] los divanes de laca con tapicería de brocado amarillo y verde mar, [...] la chaise longue de cuero y esmalte blanco marfil” etc. (10-12). 
y en el arte, es la conciencia "niveladora” feminista. Se presentan un sinnúmero de descripciones de la belleza del cuerpo de Cecilia, de sus vestidos, su pelo y sus joyas -todos elementos que estaban al servicio del placer corporal y, de ahí, material. Abundan las descripciones, breves y ligeramente sensuales, de las relaciones físicas entre Cecilia y Óscar. Pero la novela no entra en la sensualidad abierta sino con la descripción de un acto amoroso entre las dos jóvenes hermanas, vecinas de los artistas. Una de ellas, Josefina, se cree también poeta. Impulsada por la lectura de Noches de amor de Musset (133), la "fogosa adolescencia" de la joven poeta "ha descubierto los placeres sexuales en las páginas de un libro erótico y descarnado, hasta la más intoxicante embriaguez de los sentidos” (135-36). Josefina le dice a su hermana: "Figúrate dos jóvenes buenos mozos [...] enloquecidos por un deseo maravilloso, nos morderían los rosados botones del seno mientras pulsaran las carnes estremecidas para ir penetrando en el secreto del placer infinito, hondos, suaves, dulces” (138). Cuando conciernen a Cecilia -artista mundana, sofisticada en los placeres corporales- las descripciones están llenas de ironía autoconocedora, pero para las jóvenes son un descubrimiento vital. Se estimulan por la lectura del libro -releído y recontado, es decir reinterpretado, por Josefina y es una lectura que constituye una retextualización del cuerpo femenino. Sin poderse contener, "el deseo las absorbe, el placer las acicata [...] [S]e besan, imitando la descripción del capítulo que las excitara con el relato de lo que desconocían” (139-140). Despierta a la sexualidad, y sintiendo "unos deseos locos de sentir[se] enamorada, deseada profundamente, querida [...]” (134), Josefina está lista para ser seducida. Óscar logra conquistarla, también a través de la palabra, de la textualización: "La táctica del seductor consistía en ir despertando con ayuda de los libros la natural exaltación de la joven artista” (147); le envía libros de Alarcón, Balzac, Blasco Ibáñez, el Manon Lescaut, y una novela “descarnada, pero sublime y bella” (ibid.). No tardan en entrar en relaciones amorosas el novelista de gran experiencia y una "ipobrecita niña incauta que supo amar ampliamente, seducida por la carne y el fuego de su lozana juventud!” (175), con las consecuencias naturales que estas relaciones producen.

La novela de Garbalosa participa de la dinámica de la vida humana y la sociedad habanera de la época. Josefina, así como sus dos hermanas, representan a la naciente clase trabajadora femenina; recién egresada de un prestigioso colegio internado, Josefina tiene que buscar empleo, situación que le provoca ideas de independencia económica, moral y social:

Sépalo Vd [le dice Josefina a Óscar] [...], desde el próximo lunes comienzo a ir a la oficina, yo, la hija de un médico célebre que murió pobre porque quiso ser honrado [...] [L]as oficinistas decentes resultan más útiles y morales que las 
burguesas haraganas y presumidas [...] Sueño con ser oficinista. Con andar cómoda y ser dueña de mis actos. (121-22)

Por otro lado, la conciencia del cuerpo, mientras le revela a la mujer de sus encantos y le permite vivir plenamente en su momento, trae consigo otra conciencia, la del tejido material de la existencia humana, del transcurso del tiempo y los estragos del mismo. Con el pasar de los años, pasa la juventud y adviene el fastidio del diario vivir y los cambios en el cuerpo: “iEnvejecer! ¡Qué dolorosa realidad!” (66), observa Cecilia. Queda claro que la perspectiva narrativa valoriza el proceso de la dinámica vital en términos de la apariencia estética y genérica. Por un lado, la conciencia de la materialidad de lo femenino cuenta con la pérdida de los encantos como consecuencia del embarazo: “dejaba de ser seductora y escultural” la mujer encinta (54). Por otro lado, al saber lo que ha hecho Óscar con Josefina, Cecilia decide matarlo y suicidarse ella al mismo tiempo, porque el hombre en su vejez deja de tener los encantos físicos tan importantes para un ambiente en el que priva la estética: "así [piensa Cecilia] le evitaría la vergüenza de la vejez que pone al hombre impotente y ridículo tan pronto cesa la virilidad” (201).

El erotismo literario como conciencia de lo corporal tiene una fuente consecuente en el naturalismo -la descripción gráfica de los aspectos más bajos de la sociedad a partir de la observación minuciosa de la realidad circundante. En el prólogo de la novela, Graziella Garbalosa admite su deuda con el naturalismo, indicando ingenuamente que la novela es "una exacta copia de la realidad" (8). Con esa conciencia, Garbalosa va mucho más allá de Bobadilla en su "espíritu de observación y estudio psicológico" (citado anteriormente). Bobadilla se hunde en un erotismo siempre más degenerado del voyeurismo, de lo ilícito, las drogas y la exaltación de la belleza de la amada muerta. Garbalosa trata en forma explícita y descarnada las consecuencias naturales del erotismo (el embarazo de la joven vecina), que terminan trastornando la conciencia erótica del cuerpo. Así como ejecutó una franca descripción de las escenas amorosas, nombrando las partes del cuerpo vedadas a la pluma femenina hasta entonces, Garbalosa lleva esa técnica y ese vocabulario descriptivos a otra retextualización -es decir, reapropiación- del cuerpo femenino cuando presenta un aborto y sus consecuencias. El discurso de la comadrona que "reconoce" a Josefina como parte del procedimiento médico refleja lo que habrán sido los movimientos efectuados por Josefina en el acto sexual: “'Sube las piernas [...] Abre, abre tus piernas, hijita [...]' [L]e introduce por el sitio conveniente el mefistofélico aparato [...]” (177-78). En este caso se trata del aparato que provocará el aborto, pero la descripción asimismo recuerda el acto del desflorecimiento de la virgen. El aborto provocado por la comadrona (en vista del conocimiento deficiente y de las leyes, ese procedimiento es necesariamente 
anticientífico e ilegal) no resulta como fue previsto, y Josefina sufre varios días de una enfermedad desastrosa, manteniendo el secreto de su condición ante su familia casi hasta el último momento. Garbalosa describe la expulsión del feto y la desaparición del mismo por medio de "un tirón a la cadena” del inodoro en el baño de la casa familiar en párrafos de un descarnado realismo:

\begin{abstract}
expulsa en el inodoro algo [...]. Al fin, tras un cuarto de hora, la placenta desciende y ella jadeante se levanta del receptáculo para ver lo que ha expulsado. Sus pupilas se dilatan, sus crispadas manos tiemblan [...] En una bolsita de agua unida a mucha basura de gelatinas y sangre, un muñequito de celuloide navega moviendo sus bracitos y rodillas [...] De pie, sangrante, mira aquel fruto de su vida sin poder llorar [...] espantada, le da un tirón a la cadena, y entre el ruido estridente de borbotones de agua, el muñeco desciende aplastado contra las paredes del tubo, por donde va deshaciéndose al impulso de la corriente, en partículas de carnes embrionarias. (188-89)
\end{abstract}

En última instancia, sin embargo, la mujer artista, creadora -la bailarina-, actúa para "nivelar” y liquidar "al macho encubierto de vanidad, egoísmo y astucia [...]" (151). Cecilia la niveladora es vista como "la hembra sensible y perfecta en su condición de abastecedora de la especie, y robustecedora del germen y el ser [...]" (151). La novela es, según lo explica el mismo prólogo, una tesis que la autora irá "desarrollando en mis futuros libros, encaminados hacia un solo fin [...] para que logremos nosotras, las madres de la Humanidad, un camino más cómodo por donde ir, cargadas con el fardo de dolores que nos ha legado la Vida” (7).

Efectivamente, este tema feminista al estilo de los años veinte volverá en varias de las novelas posteriores de Garbalosa, pero siempre unido a la preocupación por la variada expresión que pueden tomar las reflexiones feministas ficticias. En su volumen de cuentos titulado Narkis y publicado en México en 1948, Garbalosa reproduce fragmentos de cartas del ilustre Enrique José Varona, de una correspondencia llevada a cabo entre agosto 1922 y septiembre 1923 y en la que Garbalosa ha pedido la opinión de Varona sobre "la novela”. En repetidas ocasiones éste le aconseja a la autora que "refrene" su imaginación y su fantasía (s.p.). Sin embargo, con esta novela Graziella Garbalosa ha cumplido una función única. Quizás a la novela de "tesis" -como autodenominó Garbalosa su primera novela-pueda faltarle “arte”, así como se define tradicionalmente, pero también puede ser necesaria para lograr grandes rupturas sociales y artísticas. Kristeva mantiene que la escritura es la cima donde se afirma el devenir del sujeto (98). Así como era necesario que las dos hermanas de su primera novela se concienciaran de los placeres posibles de su cuerpo a través de la lectura para reconocer ese cuerpo como materialidad, con la escritura de la novela misma Graziella Garbalosa inició en Cuba la retextualización-y por tanto la 
concienciación y reapropiación- del cuerpo femenino a partir del sujeto femenino mismo. E hizo tal a través de la expresión de un erotismo doblemente prohibido a la sazón: no sólo de mujeres, o entre mujeres, sino entre hermanas.

Después de 1923, Cuba pierde de vista a Graziella Garbalosa, que reside un tiempo en México, donde sigue publicando y participa de la vida de la bohemia capitaleña. ${ }^{11}$ En el prólogo de la segunda novela que da a luz Garbalosa en 1923, el año siguiente de La gozadora del dolor y titulada El relicario. Novela de costumbres cubanas, la autora caracteriza su producción literaria hasta el momento:

Primero les di una Juguetería de amor, pleno de juguetes bonitos y baratos; después una Gozadora del dolor, ebria de tropical erotismo; ahora que habéis gozado la dulce ingenuidad y el encendido atrevimiento, les brindo este libro de suaves esmaltes emeraldinos y azules, con tonalidades rosa y nieve. Primero la juventud, siguiéndole la pubertad, a continuación las remembranzas infantiles. (5)

Efectivamente El relicario... parece más bien un volumen de memorias de Graziella ante "el cadáver de la infancia [suya]" (6), haciendo contar a una joven "las escenas del pasado" (21) de una niña imaginativa, con un "poder de imitación asombroso" (33). El libro presenta las memorias fragmentadas de "la exótica Gisela" (9), escritas cuando ésta ya cumplió los veinticinco años (31) en "el año mil novecientos veinte y dos [...], [año] transcendental para mi país, que sufre el desequilibro del siglo reinante [...] con más armónico descabellamiento que nación alguna en todo el globo terráqueo" (29). En primera persona del singular, cuenta la infancia y la adolescencia de Gisela hasta la edad de quince años, la residencia en la capital cubana entre los bohemios, anarquistas y desadaptados, a través de incidentes familiares y pueblerinos, esparcidos de reflexiones filosóficas y morales, en un todo ameno y dulce. En esta novela también Graziella Garbalosa se inserta en las tendencias novedosas del momento. El relicario... la confirma como autora de experimentos literarios, siempre preparada a llevar la delantera en actos de escritura abiertamente autoconsciente. Se expresa la conciencia de que la realidad descrita es

11 En la biblioteca del Instituto de Literatura y Lingüística en La Habana se conserva un pequeño álbum que al parecer pertenecía a la hija de Graziella Garbalosa. En él se encuentran no sólo preciosas pinturas efectuadas y firmadas por la escritora, sino también pequeños poemas y frases de afecto de varios grandes artistas que compartían la vida artística del México de los años treinta: Carlos Pellicer, Víctor Manuel, Massaguer y aun dibujos firmados por Diego Rivera. Este último al parecer comenzó un Desnudo de Graciela Garbalosa [sic] en 1956, pintura que quedó inconclusa (http:// www.jornada.unam.mx/1999/nov99/991103/cul1.html y otros sitios de la red). El ambiente y la época representados en Más arriba está el sol se recrea en la reciente película sobre la vida de Frida Kahlo. 
escrita: "Me confesaré con el público [...] escribiré mi vida [...]. Las letras negras fueron dejando el alma clara. Comencemos a leer sus confesiones [...]" (28).

Las novelas posteriores de la "etapa cubana" de Graziella Garbalosa de los años veinte del pasado siglo son Una mujer que sabe mirar (publicada en México en 1927), y Más arriba está el sol (publicada en La Habana en 1931 pero escrita en México en 1927 y de ambiente cubano y mexicano). La primera de éstas tiene lugar en La Habana; allí la protagonista vive con su hija pequeña en una pensión donde los otros huéspedes constituyen un microcosmos de la sociedad habanera urbana, fenómeno nuevo en la narrativa del siglo veinte:

[...] la cómica vieja, [...] los estudiantes de la azotea, [...] el joven doctor, [...] el emigrante retirado, [...] el oficinista metódico, [...] la jamona viuda, [...] el sajón hermético, [...] el judío sonriente, [...] las encascarilladas y flacas [...] solteronas, [...] la dama exgalante y octogenaria, [...] la muchacha clorótica de romántico y clandestino concubinato [...] etc. (41-42)

En ambas novelas la autora mantiene su primera obsesión, el feminismo del odio hacia el hombre y el deseo de mejorar la situación de la mujer. En Más arriba está el sol, por ejemplo, escribe: "Para las familias de villorios y aldeas y hasta de ciudades, el ideal del hombre es tener mujer sana y bonita, paridora de hijos, confeccionadora de guisados y sin otra preocupación ni trabajo que la limpieza del hogar" (69). Sin embargo, y de un feminismo muy de nuestra época, está asimismo consciente de que las mujeres contribuyen a este estado de cosas; ellas han internalizado las costumbres burguesas y provincianas: "Para la mujer, el ideal consiste en que el marido sea de finos ademanes e influyente con los contertulios al círculo social; y si además de eso puede presumir de bonita vivienda, muebles a la moda, modisturas económicas [...] es indiscutiblemente feliz" (69-70).

En ninguna de sus obras posteriores Graziella Garbalosa vuelve a tocar el erotismo y el realismo abierto y descarnado de su primera novela. Sin embargo, aun en esos años veinte del siglo veinte, la autora domina con maestría los dobles sentidos y los recursos narrativos de densa significación. Por ejemplo, a través del simple recurso de los títulos de capítulos, en Más arriba está el sol establece una relación estrecha y significativa entre los eventos de la historia mundial de la época y los momentos claves de la vida matrimonial de la protagonista Adelaida: "Ruptura de hostilidades”, "El bombardeo”, “Atrincherada”, "El relevo”, “La batalla final”, "El armisticio”, etc. Así, entre los aspectos vanguardistas de innovación estructural narrativa ya atisbados en su primera novela, pero que habían quedado a la sombra de la expresión abierta de la sexualidad y sus consecuencias, se entretejen el proceso de la escritura (y una consecuente autorreferencialidad y juego con el sujeto -femenino- productor del texto y con la voz narrativa), la cuestión de la relación 
entre realidad y ficción, o la calidad de la inspiración creativa y del realismo en la novela. Por su producción vanguardista, de atrevido estilo y contenido, y por su conciencia de las preocupaciones teóricas en materia de expresión narrativa, ${ }^{12}$ se debe contar a Graziella Garbalosa como más avanzada que los escritores (y mucho más que las escritoras) de su época.

Susana Montero resume una apreciación de Graziella Garbalos diciendo que su "audaz obra narrativa, subvertidora de algunos de los más rancios y profundos mitos de la femineidad -por ejemplo el de la sublimación del sufrimiento de las mujeres en tanto crisol de pureza moral- resultó prácticamente silenciada" $(2000,4)$. A más de esa audacia subvertidora de la cuestión feminista habría que reconocerle a Graziella Garbalosa asimismo una profunda autorreflexión sobre el proceso de la escritura y la función del arte en la conciencia humana, consecuente con las tendencias más vanguardistas de la narrativa. En efecto, el pensador cubano Enrique José Varona incorporó a Garbalosa en la galería de escritores y artistas de vanguardia -llamados "Los raros” por Rubén Darío- al concluir su resumen de la autora diciendo que "la crítica la tildará de desigual, pero tendrá que reconocerla original. Lo que es mucho más raro” (en Garbalosa, Narkis, s.p.). Este trabajo ha sido un primer intento de reconocerle los múltiples méritos a esta "audaz" autora cubana “original y rara”, pero olvidada aun hoy hasta el silencio.

\section{BiBLIOGRAFÍA}

Adán, Martín, “Graziella Garbalosa, Una mujer que sabe mirar”. Amauta, II/ii, \#13.

Bobadilla, Emilio. En la noche dormida. (Novela erótica). [1914]. Madrid: Ed. Pueyo, 1920.

Davies, Catherine. A Place in the Sun? Women Writers in Twentieth-Century Cuba. Londres: Zed Books, 1997.

Diccionario de la literatura cubana. 2 vols. La Habana: Ed. Letras Cubanas, 1980.

Felski, Rita. The Gender of Modernity. Londres: Harvard UP, 1995.

Fowler, Víctor. La maldición. Una historia del placer como conquista. La Habana: Ed. Letras Cubanas, 1998.

Garbalosa, Graziella. La juguetería del amor. La Habana: Impr. Rambla Bouza, 1920.

La gozadora del dolor. La Habana: Impr. El Siglo XX, 1922.

\footnotetext{
12 Como muestra de (otro) ejemplo, en Una mujer que sabe mirar Garbalosa caracteriza a los protagonistas, muy de manera semiótica, como "signos [que] pasan las páginas" (5).
} 
El relicario. Novela de costumbres cubanas. La Habana: Impr. Rambla Bouza, 1923.

Una mujer que sabe mirar. México: Eda Mexicana, 1927.

Más arriba está el sol. La Habana: P. Fernández, 1931.

“Julio Antonio Mella en México”. Bohemia (17 septiembre 1933): 8-9 y 59.

Narkis. Diez leyendas y cuentos, antiguos y modernos en versos clásicos y libres. México: 1948.

González Curquejo, Antonio (comp.). Florilegio de escritoras cubanas. 3 tomos. La Habana: Lib. e Imp. ‘La Moderna Poesía’, 1910, 1913, 1919.

González Pagés, Julio César. En busca de un espacio: Historia de mujeres en Cuba. La Habana: Ed. de Ciencias Sociales, 2003.

Hernández Catá, Alfonso. Novela erótica. Madrid: M. Pérez Villavicencio Ed., 1909.

Historia de la literatura cubana 2 vols. La Habana: Ed. Letras Cubanas, 2003.

<http://www.jornada.unam.mx/1999/nov99/991103/cul1.html>

Kirkpatrick, Gwen. The Dissonant Legacy of 'Modernismo': Lugones, Herrera y Reissig, and the Voices of Modern Spanish American Poetry. Berkeley: U of Los Angeles P, 1989.

Kristeva, Julia. The Kristeva Reader. Toril Moi, ed. Nueva York: Columbia UP, 1986.

Litvak, Lily. Erotismo fin de siglo. Barcelona: Antoni Bosch Eds., 1979.

Mañach, Jorge. “Dos libros de mujer”. El Diario de la Marina (ed. tarde, 30 enero 1924).

Montero Sánchez, Susana. "Primera advertencia acerca de las desventajas y riesgos seculares de ser elegida musa”. Sic. Revista Literaria y Cultural 6 (Santiago de Cuba, enero-marzo 2000): 3-5.

La narrativa femenina cubana, 1923-1958. La Habana: Ed. Academia, 1989.

Romo Garbalosa, José Alberto. Comunicación personal, noviembre de 2006.

Sommer, Doris. Foundational Fictions. The National Romances of Latin America. Berkeley: U of California P, 1991. 